Cox, J. L. (1979) Amakiro: a Ugandan puerperal psychosis? Social Psychiatry, 14, 49-52.

Emerald Project (2016) Butabika National Mental Health Hospital. Available at http://www.emerald-project.eu/the-group/consortium/ butabika-national-referral-and-teaching-mental-hospital (accessed 6 June 2016).

Mental Disability Advocacy Centre (2014) Psychiatric Hospitals in Uganda: A Human Rights Investigation. MDAC.

Ndyanabangi, S., Basangwa, D., Lutakome, J., et al (2004) Uganda mental health country profile. International Review of Psychiatry. $16,54-62$.

Okello, E. S. \& Neema, S. (2007) Explanatory models and helpseeking behavior: pathways to psychiatric care among patients admitted for depression in Mulago Hospital, Kampala, Uganda Qualitative Health Research, 17, 14-25.

Petersen, I., Ssebunnya, J., Bhana, A., et al (2011) Lessons from case studies of integrating mental health into primary health care in South Africa and Uganda. International Journal of Mental Health Systems, 5, 8. DOI https://doi.org/10.1186/1752-4458-5-8.
Sartorius, N. (2007) Stigma and mental health. Lancet, 370, 810-811. Ssebunnya, J., Kigozi, F., Lund, C., et al (2009) Stakeholder perceptions of mental health stigma and poverty in Uganda. BMC International Health and Human Rights, 9. DOI https://doi. org/10.1186/1472-698X-9-5.

Ssebunnya, J., Kigozi, D., Kizza, D., et al (2010) Integration of mental health care in a rural district in Uganda. African Journal of Psychiatry, 13, 128-131. Available at http://www.ncbi.nlm.nih.gov/ pubmed/20473474 (accessed 6 June 2016).

World Bank (2016) World databank (online). Available at http:// www.worldbank.org/en/country/uganda/overview (accessed 6 June 2016).

World Health Organization (2006) WHO-AIMS Report on Mental Health System in Uganda, WHO and Ministry of Health, Kampala, Uganda. Available at http://www.who.int/mental_health/uganda who aims report.pdf (accessed 6 June 2016).

World Health Organization (2016) Country overview (online). Available at http://www.who.int/countries/uga/en (accessed 6 June 2016).

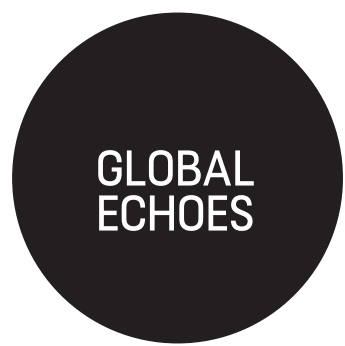

\title{
'I chained him to protect him from the spirits.' What are the challenges for psychiatrists in India?
}

\author{
Sukhmeet Singh
}

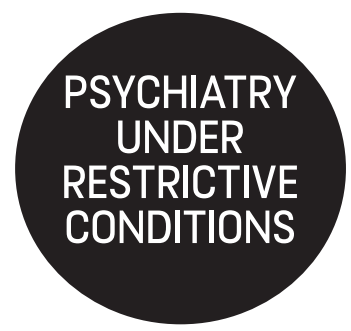

Approximately $20 \%$ of the adult Indian population are affected by a psychiatric disorder that requires intervention from a mental health professional (Math \& Srinivasaraju, 2010). In spite of this, the provision of mental healthcare is poor. Therefore, to learn more, between July and August 2014 I undertook a 4-week elective at the Psychiatry Department of Sawai Man Singh (SMS) Hospital in Jaipur, Rajasthan, India. The Psychiatry Department was founded in 1952. It has a total of 332 beds, with nearly 20000 patients admitted per year and an attendance of nearly 100000 annually at the out-patient department.

I wanted to go to India after reading a report about someone named Keshava, in Davangere district, Karnataka (Nagaraj, 2012). He was diagnosed with schizophrenia in his early 20s. Once his second course of medication had finished, his family had no money to pay for more and were not aware of the availability of free antipsychotics. They felt they had no choice but to handcuff him and when that was not enough to contain his behaviour they took to bricking him up in a room. There, deprived of sunlight and a toilet, the man remained for the next decade. People in the village began to forget about his existence and when local journalists attempted to investigate what had happened to this missing person, his mother informed them that he had died. Once his case had been reported in the local news media, regional officials took action and arranged for his admission.

\section{Consequences of stigma and discrimination}

When I came to India I did not expect that I would encounter any extreme cases like that of Keshava. Unfortunately, I did. I met a 30-year-old man on a round of the admissions ward. His mother had brought him to hospital because she said that his mind was 'broken'. She said that the problems had started 14 years ago but had recently worsened. The senior resident moved the patient's shirt downwards to reveal an iron chain tied around the patient's neck, kept in place by a padlock. The patient's mother stated that she had put the chain on only for the last $2^{1 / 2}$ months. Given the amount of rust on the chain I found that hard to believe. She explained that she 'chained him to protect him from the spirits', which she believed were the cause of the symptoms. The resident also found marks on the patient's wrists and ankles, presumably from shackles. The patient's mother was told to remove the chain around his neck but she was not able to due to the rust in the padlock.

The patient was not able to concentrate. He openly responded to hallucinations, was laughing and repeated the questions that the staff asked him. On discussion with the residents they stated that his prognosis would likely be very poor because of 
the long, protracted course of his condition and the resulting cognitive decline.

The patient in fact improved over the next few days. His appearance was neater, there were no signs of infection where the chains and shackles had been and his mental state appeared to be better. He was no longer responding to auditory hallucinations. This patient's case demonstrated the consequences of stigma and discrimination. His family were ashamed of him and he was isolated both physically and socially. The causes of stigma in a situation like this are complex. It can be caused by a lack of awareness of mental illness, which is compounded by a low level of education. The causes and consequences of stigma may be synergistic. For instance, poverty may be a consequence of stigma but will also exacerbate it (Shrivastava et al, 2012).

\section{Role of the family}

Involving the patient's family in the above case was essential. Families play a more extensive role for psychiatric patients than in the West. The proportion of patients living with the family is over $98 \%$, compared with only $50 \%$ in the West (Avasthi, 2011). Indian families assume the caring role because of interdependence and the paucity of trained mental health professionals. Indian families are close, resilient and enduring. Joint families were the norm in India but with the economic development of the country there are now more nuclear families, although they still have some support from nearby members of the extended family.

The members of an Indian family typically feel intense emotional interdependence, empathy, closeness and loyalty. The integration of families into the care of people with mental health problems in India began in the 1940s, with Dr Vidya Sagar, superintendent of Amritsar Mental Hospital, who allowed relatives to stay in open-pitched tents on campus. The patients experienced symptomatic remission more quickly and were then taken back home (Avasthi, 2011). The advantage of family involvement is that it takes pressure away from psychiatric staff, which is especially important in a resource-poor setting. The traditional joint families allow for diffusion of the burden of care.

A study by Sharma et al (1998) found that patients in Liverpool with schizophrenia were less socially integrated than patients in Bangalore, something the authors attributed to the involvement of family in maintaining strong social ties. The obvious difficulty with a model of treatment reliant on support from family is the problem of people who have family who are either unable or unwilling to care for them.

\section{Role of faith healing}

Another problem with a reliance on the family to provide support for people with mental health disorders in India is that the family often regard faith healing as more effective than medical interventions. Many Hindu people take their family members to places such as the Mehandipur Balaji mandir, a temple dedicated to Hanuman, where I witnessed what some might call the site's power to exorcise the pret aathma which they believe causes mental illness. In fact, the site is so infamous that my driver seemed scared to accompany me into the shrine; I was left to go in alone. As I walked through a narrow corridor surrounded by bars on either side of me, dodging the occasional monkey, and its droppings, I was shocked by the people who were rushed through the bustling crowd by their families because they were unwell. There were people with quite obvious catatonic features.

Inside the temple I saw a large fire fuelled by cowpats and the sweet patasas thrown by pilgrims to keep the fire burning. The thick smoke from this fire wafted through into a second room. There, throngs of people who were visibly unwell danced to expel the spirits while pilgrims did pooja and family members chanted. As I left the temple, I saw a woman on the ground who was clearly in a catatonic state. People obviously seemed to place a lot of faith in this temple.

Referral to psychiatric care in India depends on family and friends' knowledge of the services available. In a study of 76 patients attending the out-patient department in SMS, Jain et al (2012) found that $39.5 \%$ of patients had first contacted faith healers and another $16.5 \%$ consulted faith healers after attending psychiatrists. The reasons why family members might consult a faith healer are complex and include the fact that the practitioner might take a more positive approach, provide a positive prognosis (Henry, 1977), and use explanatory models of illness and treatments that patients understand more readily. Also, traditional healers are more accessible to rural populations than psychiatrists (Thara et al, 2004).

In a review, Levin (2009) concluded that the mechanism through which faith healing works might relate to a number of factors: hope, learned optimism, positive illusions, opening up and the placebo effect. The mechanism might also relate to something that is more innate than the culturally based construct of religion. Vaillant (2013) defined spirituality as the amalgam of eight positive emotions that bind us to each other and our experience of a higher power: love, hope, joy, forgiveness, compassion, faith, awe and gratitude. He argued that the practice of psychiatry and psychotherapy cultivates the patient's negative emotions without supporting the positive emotions; 'an attitude of gratitude' might be more readily promoted by faith healers who emphasise a patient's spirituality.

\section{Conclusion}

The challenges faced by psychiatrists in India are diverse and complex. While some of these will be easier to address with increased government funding and educational interventions for medical students, some are harder for clinicians to address, including poverty, poor education, the lack of community mental healthcare, the reliance on faith healing and the stigma and discrimination felt by people with mental health problems. 


\section{References}

Avasthi, A. (2011) Indianizing psychiatry - is there a case enough? Indian Journal of Psychiatry, 53, 111-120.

Henry, E. O. (1977) A north Indian healer and the sources of his power. Social Science and Medicine, 11, 309-317.

Jain, N., Gautam, S., Jain, S., et al (2012) Pathway to psychiatric care in a tertiary mental health facility. Asian Journal of Psychiatry, 5, 303-308.

Levin, J. (2009) How faith heals: a theoretical model. Explore, 5, 77-96.

Math, S. B. \& Srinivasaraju, R. (2010) Indian psychiatric epidemiological studies: learning from the past. Indian Journal of Psychiatry, 52 (S1), S95-S103.
Nagaraj, A. (2012) 10 years in a prison at home. Open Magazine, 10 November. Available at http://www.openthemagazine.com/ article/nation/10-years-in-a-prison-at-home (accessed 4 December 2014).

Sharma, V., Murthy, S., Kumar, K., et al (1998) Comparison of people with schizophrenia from Liverpool, England and Sakalwara, Bangalore, India. International Journal of Social Psychiatry, 44, 225-230

Shrivastava, A., Johnston, M. \& Bureau, Y. (2012) Stigma of mental illness - 1: Clinical reflections. Mens Sana Monographs, 10, 70-84.

Thara, R., Padmavati, R. \& Srinivasan, T. N. (2004) Focus on psychiatry in India. British Journal of Psychiatry, 184, 366-373.

Vaillant, G. E. (2013) Psychiatry, religion, positive emotions and spirituality. Asian Journal of Psychiatry, 6, 590-594.

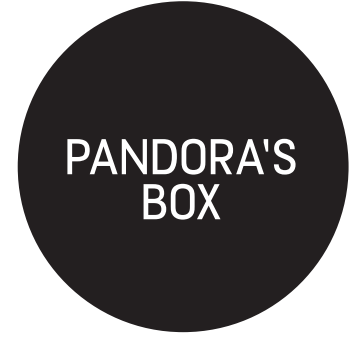

Pandora searches the world literature for evidence, news and other sources on matters of interest (doesn't shy away from controversy) to ry) to bring to the reader. She welcomes comments and suggestions (via ip@rcpsych. ac.uk)

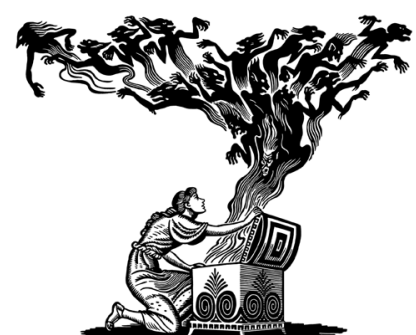

\section{Oenophiles beware}

Tf you believe that the price of your wine deter1 mines its quality, think again - your brain may be tricking you into thinking it tastes better. Researchers at Michigan State University demonstrated that the higher price creates the expectation that the quality (taste) will be better and this has a neurobiological basis. They carried out a wine-tasting session during which people were asked to taste a number of wine samples while undergoing brain functional magnetic resonance imaging (fMRI). Each sample tasting was preceded by information about the wine's price. The participants rated the pricier samples as tastier but, unbeknown to them, all samples were of the same wine! Their fMRI showed higher activation of the medial prefrontal cortex and also the ventral striatum when prices were higher. The authors conclude that the medial prefrontal cortex is involved in integrating the price comparison and thus the expectation into the evaluation of the wine. The ventral striatum, which forms the reward and motivation system, is significantly more activated with higher prices and it heightens the taste experience.

Schmidt, L., Skvortsova, V., Kullen, C., et al (2017) How context alters value: the brain's valuation and affective regulation system link price cues to experienced taste pleasantness. Scientific Reports, https://doi.org/10.1038/s41598-017-08080-0.

\section{Expressing your worries in writing cools your brain}

Wany of us are chronic worriers and go to pieces reaching for a diazepam tablet, write down your feelings, say psychologists from Michigan. It is known that error-related negativity (ERN) immediately after errors is larger in people with anxiety. In a study of college students who were identified as chronically anxious, participants were asked to complete a computer-based task which measured their response accuracy and reaction times while undergoing electroencephalography (EEG). Half the students were asked to write down their inner thoughts and feelings about the upcoming test, for 8 minutes before the task, and the other half to write about what they did the previous day. Both groups performed at the same level for speed and accuracy but the students from the expressive writing group performed the test more efficiently, in that they used fewer brain resources, with their ERN reduced. Expressive writing is known to help people deal with past traumas or stressful events and the authors argue that this simple technique can also help people, and particularly worriers, prepare for stressful tasks and to perform them with 'a cooler head', preventing burnout.

Schroder, H. S., Moran, T. P. \& Moser, J. S. (2017) The effect of expressive writing on the error-related negativity among individuals with chronic worry. Psychophysiology, https://doi.org/10.1111/ psyp. 12990

\section{Eating as your biological night kicks in can make you fat}

besity is an increasing problem. Bad diet and sedentary lifestyles are the known main culprits but a recent study implicates circadian rhythm. Circadian rhythms govern diurnal variations in important physiological functions (body temperature, heart rate, blood pressure, some hormones) and have been linked to mood disorder.

Researchers examined the relationship between the timing of food consumption and the clock hour and endogenous circadian time, content of food intake and body composition. They recruited 110 participants with average age 20 in a 30 -day crosssectional study documenting sleep and circadian behaviours within their daily routine. They found that those with high body fat consumed more of their calories 1 hour closer to the melatonin onset (which signals the beginning of the biological night) compared with those with low body fat. The lesson is that if you want to stay lean, don't mess with your biological clock: have your meals earlier in the day but also eat less and exercise more! McHill, A. W., Phillips, A. J. K., Czeisler, C., et al (2017) Later circadian timing of food intake is associated with increased body fat. American Journal of Clinical Nutrition, https://doi.org/10.3945/ ajcn.117.161588.

\section{The Neanderthal in us}

B efore becoming extinct 40000 years ago, NeanBderthals interbred with our human ancestors during their primordial migration from Africa, leaving some of their DNA in us. The Neanderthals had highly developed visuospatial skills and relied less on social activities. The extent of inheritance of their genes influences the development of our brains. Researchers from the National Institute for Mental Health (NIMH) reported in 2012 that 